\title{
DYNAMIC DENSITY: MEASURING AND PREDICTING SECTOR COMPLEXITY
}

\author{
Parimal Kopardekar, Ph.D., Titan Systems, Mays Landing, NJ \\ Sherri Magyarits, Federal Aviation Administration, Atlantic City, NJ
}

\section{The Need for Dynamic Density}

Aviation operations have exhibited steady long-term growth over the past several decades, and the aviation community expects this trend to continue. In addition to increasing traffic volume, many regions of the airspace will experience more dynamic traffic flows as more and more user preferences are accommodated. As a result, sector air traffic operations will become even more dynamic than they are today.

In the present air traffic control system, traffic management personnel use the Enhanced Traffic Management System (ETMS) 'monitor alert' parameter as a strategic planning tool to identify and predict sector traffic complexity so that strategic and tactical air traffic decisions such as flow modifications, staff planning, sector redesigns can be planned. The monitor alert parameter is based solely on aircraft count. When the number of aircraft is expected to reach a predetermined threshold for a particular sector, monitor alert delivers a red alert (i.e., high workload warning). While the number of aircraft can certainly contribute to the complexity of sector operations, it is not the only indicator, and thus does not always accurately represent the taskload experienced by the air traffic controller.

For several years, the Federal Aviation Administration (FAA) has supported the development of a better method to measure and predict sector complexity, referred to as Dynamic Density (DD), to provide a more encompassing, useful tool for today's air traffic control environment. Aside from serving present air traffic facility functions, such a metric also has applications for advanced air traffic control concepts, including dynamic resectorization, airspace redesign, and free flight. These programs depend on the ability to accurately measure and predict sector-level traffic complexity.
This paper reviews a multi-year, multiorganizational research effort to develop and validate several proposed DD metrics. It provides an overview of the DD metrics under consideration, the study approach to collect operational subjective data, and the development and validation of a 'best' DD metric.

\section{Dynamic Density Definition}

The term Dynamic Density is analogous to complexity or difficulty of a traffic situation. It originated in an RTCA Task Force 3 report [1], where it was described as "the essential factors affecting conflict rate in both en route and terminal airspace." DD can also be defined as ATC taskload, which is the basis of controller subjective workload. It is a "measure of control-related workload that is a function of the number of aircraft and the complexity of traffic patterns in a volume of airspace" [2]. For the purposes of this paper and the DD activities described herein, the term DD is defined as the collective effect of all factors, or variables, that contribute to the sector level air traffic control complexity or difficulty at any given time [3].

\section{Complexity Variables}

The factors that contribute to sector level traffic complexity have been of interest to researchers for a long time. Mogford, Guttman, Morrow, and Kopardekar [4] identified and reviewed air traffic complexity related literature dating back to 1963 . Most articles identified aircraft count, sector geometry, traffic flows, separation standards, aircraft performance characteristics, and weather as the most common factors that contribute to air traffic complexity or difficulty. Kopardekar [5] conducted a review of DD variables that different researchers and agencies identified as contributing factors to air traffic

\section{U.S. Government work not protected by U.S. Copyright}


control complexity, and uncovered a common thread of primary variables. They consisted of traffic density, traffic flow characteristics, and separation standards. For the DD research described in this paper, the variables considered for analysis depended on what each participating organization's vision was of factors that affect traffic complexity. The specific variables are described in the following sections.

\section{Research Partners}

The FAA developed a Research Management Plan (RMP) to identify all parties interested in conducting the DD research and produce a cohesive plan for doing so [6]. The RMP is a living document that provides a means for organizations to effectively use resources and eliminate duplication of effort. The DD research described in this paper was lead by ACB-330 of the William J. Hughes Technical Center (WJHTC). The research partners included Titan Systems, NASA Ames Research Center, Metron Aviation, and Mitre CAASD.

\section{Methodology}

Despite the fact that researchers have proposed many complexity variables and algorithms over the years, the validity of such metrics has not been examined using a large amount of operational data. In the DD study reported here, the researchers investigated the performance of four different DD metrics. These included metrics developed by the WJHTC and Titan Systems, two developed by NASA, and one originally developed by Wyndemere, but now represented by Metron Aviation.

The $\mathrm{DD}$ research was divided into three phases. Phases I and II both aimed at developing, refining, and executing a study to collect a large sample of subjective complexity rating data from controllers and supervisors at multiple Air Route Traffic Control Centers (ARTCCs) across the country. Phase III was the data analysis portion of the research effort, which involved the coding of the proposed metric variables into an en route decision support tool, the generation of DD output, and the comparison of the DD output to the complexity ratings, both in instantaneous and predictive modes.

\section{Phase I}

Phase I served as a pilot study for the multiCenter data collection planned for Phase II. The intent of Phase I was to refine the experimental approach for gathering complexity ratings from controller and supervisor participants. Phase I was performed at Denver Center (ZDV) in October 1999.

\section{Phase II}

Phase II consisted of a large-scale operational data collection at four ARTCCs: Atlanta Center (ZTL), Cleveland Center (ZOB), ZDV, and Fort Worth Center (ZFW). The DD researchers collected a total of 72 thirty-minute samples of traffic data from a total of 36 high and low sectors.

Using Systematic Air Traffic Operations Initiative replays, they collected complexity ratings every two minutes for each of the traffic samples from a total of 72 controllers and supervisors, resulting in over 6400 ratings.

\section{Phase III}

Phase III was performed to primarily answer the following questions:

- Can a DD metric(s) accurately capture complexity?

- Is a DD metric(s) reliable/persistent for predicting complexity starting 2 hours out?

In order to do this, the first activity in Phase III was to extract the proposed DD variables from the ETMS data. The ETMS data was used as the input for calculating $D D$ variables because it is currently used for predicting the monitor alert parameter. The researchers selected the Collaborative Routing Coordination Toolset (CRCT) developed by MITRE CAASD to produce the DD output. They selected this tool because of its ability to ingest ETMS data, and because it contained a trajectory modeler, essential to the computation of many of the metric variables. 
After coding the metrics, MITRE CAASD programmers extracted ETMS data corresponding to the traffic sample dates and times during which complexity ratings were collected and ran it through the metrics in CRCT to produce DD output values. They then gave the data to the research partners to address the following objectives:

Objective 1. Determine how accurately the DD metrics represent the subjective complexity ratings. Specifically,

- Develop a DD model (weights for different variables)

- Compare different DD metrics

- Select a 'best-fit' DD metric

- Test DD model for accuracy

Objective 2. Determine how stable the predictions are over time for the selected metric. Specifically, examine DD metric prediction performance starting from 2 hours prior to traffic sample intervals.

Figure 1 depicts the distinction between the instantaneous and predicted DD.

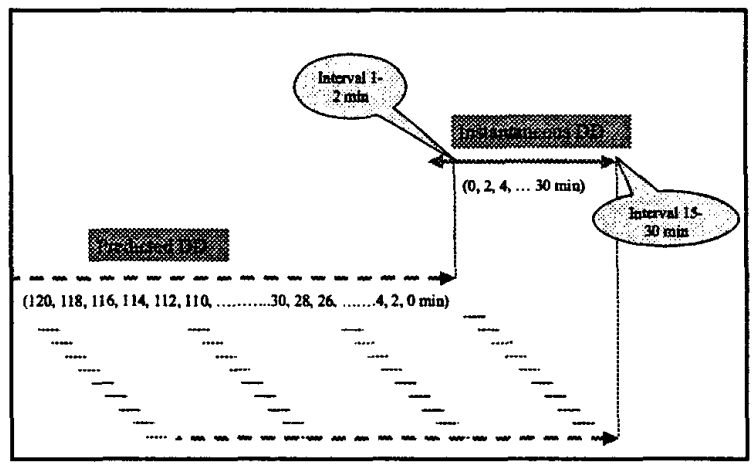

Figure 1. Instantaneous and Predicted DD

Data Analysis Approach

The researchers divided the 72 30-minute traffic samples into two groups. The first group of 60 traffic samples was used to develop the DD model (i.e., establish weights). The second group of 12 traffic samples was used to test the DD model.

For each of the 72 traffic samples, the researchers performed two types of DD calculations. The first consisted of instantaneous DD calculations (for objective 1 of accuracy testing) and the second consisted of predicted DD calculations (for objective 2 of reliability assessment).

The instantaneous DD calculations were performed at 2-minute intervals (corresponding to the same two-minute intervals at which complexity ratings were provided) for each of the 30-minute traffic samples. The predicted DD calculations were performed at 2-minute intervals up to 120 minutes prior to actual traffic sample times.

Using the first group of 60 traffic samples, DD models were constructed for the four candidate metrics: WJHTC and Titan metric, two NASA metrics, and one Wyndemere/Metron metric. Additionally, a unified model comprised of all variables from all four metrics was also developed.

The researchers used a regression method to develop the DD metric(s). Results from other methods will not be reported here, but the researchers are continuing efforts to use non-linear regression, neural nets, and other methods to improve the DD models. Only results of initial regression analysis are reported in this article.

\section{Description Of DD Metrics}

A brief description of DD metric variables is provided here. For further details and calculation methods, readers are encouraged to refer to Kopardekar [5].

\section{WJTHC/Titan Metric}

AD1 Aircraft density 1 - number of aircraft/occupied volume of airspace

AD2 Aircraft density 2 - number of aircraft/sector volume

CRI Convergence recognition index - measure of the difficulty of detecting converging aircraft with shallow angles

SCI Separation criticality index - proximity of conflicting aircraft with respect to their separation minima

DOFI Degrees of freedom index - based on maneuver options in a conflict situation

CTI1 Coordination taskload index 1 - based on aircraft distance from the sector boundary prior to hand-off 
CTI2 Coordination taskload index 2 - different formula based on the same principle as CTI1

SV Sector volume

ACSQ Square of aircraft count

In addition to above quantitative variables, the WJTHC/Titan metric also involved categorical variables such as facility type, and high and low sector type.

\section{NASA Metric 1}

The NASA-1 metric consisted of 16 variables. For details of the calculations, readers are encouraged to refer to Chatterji [7].
C1 Number of aircraft
C2 Number of climbing aircraft
C3 Number of cruising aircraft
C4 Number of descending aircraft
C5 Horizontal proximity metric 1
C6 Vertical proximity metric 1
C7 Horizontal proximity measure 2
C8 Vertical proximity measure 2
C9 Horizontal proximity measure 3
C10 Vertical proximity measure 3
C11 Time-to-go to conflict measure 1 .
C12 Time-to-go to conflict measure 2
C13 Time-to-go to conflict measure 3
C14 Variance of speed
C15 Ratio of standard deviation of speed to average speed
C16 Conflict resolution difficulty based on crossing angle

\section{NASA Metric 2}

The NASA-2 metric consisted of 8 variables. Laudeman, Shelden, Branstrom, and Brasil [8] and Sridhar, Sheth, and Grabbe describe these variables in detail [9]. The metric consisted of:

\section{N Traffic Density}

NH Number of aircraft with Heading Change greater than $15^{\circ}$

NS Number of aircraft with Speed Change greater than 10 knots or 0.02 Mach

NA Number of aircraft with Altitude Change greater than 750 feet
Number of aircraft with 3-D Euclidean distance between $0-5$ nautical miles excluding violations

S10 Number of aircraft with 3-D Euclidean distance between 5-10 nautical miles excluding violations

S25 Number of aircraft with lateral distance between 0-25 nautical miles and vertical separation less than $2000 / 1000$ feet above/below $29000 \mathrm{ft}$

S40 Number of aircraft with lateral distance between 25-40 nautical miles and vertical separation less than 2000/1000 feet above/below $29000 \mathrm{ft}$

S70 Number of aircraft with lateral distance between $40-70$ nautical miles and vertical separation less than $2000 / 1000$ feet above/below $29000 \mathrm{ft}$

\section{Wyndemere/Metron Metric}

The Wyndemere/Metron metric consisted of 10 variables. For further details, refer to Wyndemere [10].

WACT Aircraft Count within a sector WDEN Aircraft count divided by the usable volume of sector airspace.

WCLAP Number of aircraft with predicted separation less than a threshold value (e.g., 8 miles) at a particular time.

WCONVANG The angle of converge between aircraft in a conflict situation

WCONFLICTNBRS Count of number of other aircraft in close proximity to a potential conflict situation (e.g., within 10 miles laterally and 2000 feet vertically).

WCONFBOUND Count of predicted conflicts within a threshold distance of a sector boundary (e.g., 10 miles).

WALC Count of number of altitude changes above a threshold value with the sector.

WHEADVAR Count of number of bearing changes above a threshold value with the sector.

WBPROX Count of number of aircraft within a threshold distance of a sector boundary (e.g., 10 miles). 
WASP The squared difference between the heading of each aircraft in a sector and the direction of the major axis of the sector, weighted by the sector aspect ratio.

\section{Results}

\section{DD Model Development}

Using the first group of 60 traffic samples, regression was performed. The results of the regression can be summarized as follows (See Tables 1 through 5):

- All four DD metrics perform better than currently used aircraft count to represent complexity.

- Different metrics perform better for different facilities. DD performs the best for ZDV and the worst for ZOB implying that there are still some complexity variables that may be missing for $\mathrm{ZOB}$.

- WJTHC/Titan metric performs best for all facilities combined

- Unified DD metric (i.e., variables from all four proposed metrics) provides the best results in all conditions

Tables 1 through 5 indicate the $R$-values of the regression for ZDV, ZTL, ZFW, ZOB, and all facilities combined.

Note: $\mathrm{S}$ refers to supervisor ratings, $\mathrm{C}$ refers to controller ratings, $L$ refers to low altitude sectors and $\mathrm{H}$ refers to high altitude sectors.

Table 1. Regression Results (R Values) for ZDV

\begin{tabular}{|c|c|c|c|c|c|c|c|c|c|}
\hline Metrics & $\begin{array}{l}\text { S\&C. } \\
\text { H\&L }\end{array}$ & S\&C.L & $\mathrm{SsC}, \mathrm{H}$ & $\begin{array}{c}\mathrm{C}, \\
\mathrm{H} \& \mathrm{~L}\end{array}$ & S. H\&L & $\mathrm{C}, \mathrm{H}$ & $\mathbf{S}, \mathbf{H}$ & $C, L$ & S.L \\
\hline $\begin{array}{l}\text { Airrraf } \\
\text { Court }\end{array}$ & 0.730 & 0.742 & 0.740 & 0.713 & 0.755 & 0.796 & 0.753 & 0.701 & 0.796 \\
\hline $\begin{array}{l}\text { Tech } \\
\text { Center }\end{array}$ & 0.740 & 0.809 & 0.748 & 0.745 & 0.744 & 0.744 & 0.787 & 0.787 & 4 \\
\hline NASA-I & 0.728 & 0.802 & 0.773 & 0.719 & 0.750 & 0.771 & 0.724 & $0.78 \mathrm{~A}$ & 0.853 \\
\hline Meron & $6=$ & 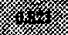 & 6 & 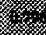 & 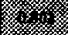 & 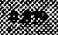 & $6=0$ & $8=$ & 0.860 \\
\hline NASA-2 & 0.365 & 0.520 & 0.514 & 0.332 & 0.408 & 0.525 & 0.511 & 0.467 & 0.603 \\
\hline All & & & & & & & & & \\
\hline & & & & & & & & & \\
\hline
\end{tabular}

Table 2. Regression Results (R Values) for ZTL

\begin{tabular}{|c|c|c|c|c|c|c|c|c|c|}
\hline Metrics & $\begin{array}{l}\text { S\&C. } \\
\text { H\&L }\end{array}$ & S\&C, L & StC, H & $\begin{array}{c}\text { C, } \\
\text { HiL }\end{array}$ & s, H\&L & C, $\mathbf{H}$ & $\mathrm{S}, \mathrm{H}$ & $\mathbf{C}, \mathbf{L}$ & S, L \\
\hline $\begin{array}{l}\text { Aircrat } \\
\text { Couutt }\end{array}$ & 0.454 & 0.193 & 0.398 & 0.459 & 0.448 & 0.426 & 0.370 & 0.175 & 0215 \\
\hline $\begin{array}{l}\text { Tech } \\
\text { Center }\end{array}$ & 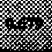 & 0.326 & 0.509 & 4 & 0.673 & 0.554 & 0.496 & 0.336 & 0.384 \\
\hline NASA-1 & 0.678 & 0.363 & ( & 0.689 & 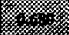 & 4 & 0.538 & 0.387 & 0.391 \\
\hline Metron & 0.626 & (2) & 0.466 & 0.641 & 0.627 & 0.501 & 818 & 6.8 & 3 \\
\hline NASA-2 & 0.325 & 0.161 & 0.342 & 0.311 & 0.347 & 0.383 & 0.365 & 0.166 & 0.212 \\
\hline All & & & & & & & & & \\
\hline & & & & & & & & & \\
\hline
\end{tabular}

Table 3. Regression Results (R Values) for ZFW

\begin{tabular}{|c|c|c|c|c|c|c|c|c|c|}
\hline Metrics & $\begin{array}{l}\mathrm{SsC}, \\
\mathrm{H} \text {, }\end{array}$ & $\sec , \mathrm{L}$ & $\mathrm{s \& C}, \mathrm{H}$ & $\begin{array}{c}\text { C. } \\
\mathrm{H} \& \mathrm{~L}\end{array}$ & S. $\mathrm{H} \& \mathrm{~L}$ & $\mathrm{C}, \mathrm{H}$ & S, H & C.L & S, L \\
\hline $\begin{array}{l}\text { Aircraft } \\
\text { Count }\end{array}$ & 0.540 & 0.403 & 0.509 & 0.480 & 0.619 & 0.415 & 0.623 & 0.432 & 0.373 \\
\hline $\begin{array}{l}\text { Tech } \\
\text { Center }\end{array}$ & 0.568 & 0.521 & 0.545 & 0.539 & 0.642 & 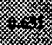 & 0.626 & 0.651 & 0.494 \\
\hline NASA-I & 10 & 0.458 & (1) & 0.555 & $8 x$ & 0.597 & 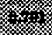 & 0.511 & 0.495 \\
\hline Metron & 0.556 & 8 & 0.572 & 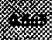 & 0.592 & 0.576 & 0.616 & 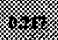 & 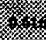 \\
\hline NASA-2 & 0.393 & 0.437 & 0.420 & 0.364 & 0.439 & 0.383 & 0.477 & 0.446 & 0.478 \\
\hline $\mathrm{A}$ & & & 2 & & & & & & \\
\hline & & & & & & & & & \\
\hline
\end{tabular}

Table 4. Regression Results ( $R$ Values) for ZOB

\begin{tabular}{|c|c|c|c|c|c|c|c|c|c|}
\hline Metries & $\begin{array}{l}\text { S\&c, } \\
\text { H\&L }\end{array}$ & $s \& c, L$ & S\&C. H & $\begin{array}{c}c \\
\text { c, } \\
\text { H\&L }\end{array}$ & S. H\&I & C.H & S.H & $\mathrm{C}, \mathrm{L}$ & S. L \\
\hline $\begin{array}{l}\text { Aireraft } \\
\text { Count }\end{array}$ & 0.360 & 0.310 & 0.230 & 0.348 & 0.402 & 0.230 & 0.268 & 0.280 & 0.364 \\
\hline $\begin{array}{l}\text { Tech } \\
\text { Center }\end{array}$ & 0.422 & 0.392 & 0.402 & 0.434 & 0.501 & 0.379 & 0.488 & 0.415 & 0.467 \\
\hline NASA-1 & (2) & 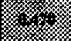 & צ' & 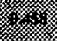 & 4 & 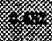 & 8 & 0.468 & 1) \\
\hline Metron & 0.425 & 0.437 & 0.448 & 0.436 & 0.459 & 0.429 & 0.533 & 284 & 0.447 \\
\hline NASA-2 & 0.248 & 0.332 & 0.298 & 0.218 & 0.309 & 0.297 & 0.477 & 0.304 & 0.408 \\
\hline 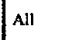 & & & & & & & & & \\
\hline & & & & & & & & & \\
\hline
\end{tabular}


Table 5. Regression Results (R Values) For All Facilities

\begin{tabular}{|c|c|c|c|c|c|c|c|c|c|}
\hline Metrics & $\begin{array}{l}\text { S\&C, } \\
\text { H\&LI }\end{array}$ & S\&C, L & $\mathrm{S \& C}, \mathrm{H}$ & $\begin{array}{c}\text { C, } \\
\text { H\&L }\end{array}$ & $\mathrm{S}, \mathrm{H} \& \mathrm{~L}$ & C, $\mathrm{H}$ & S, H & $C, L$ & S, L \\
\hline $\begin{array}{l}\text { Aircraft } \\
\text { Coumt }\end{array}$ & 0.479 & 0.445 & 0.444 & 0.445 & 0.522 & 0.423 & 0.507 & 0.374 & 0.423 \\
\hline $\begin{array}{l}\text { Tech } \\
\text { Center }\end{array}$ & 4 & 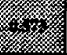 & 0.511 & \% & k & 0.512 & 0.538 & 4 & x. \\
\hline NASA-I & 0.541 & 0.493 & 3 & 0.516 & 0.580 & 1) & k. & 0.468 & 0.544 \\
\hline Metron & 0.483 & 0.439 & 0.507 & 0.467 & 0.511 & 0.498 & 0.536 & 0.431 & 0.468 \\
\hline NASA -2 & 0.315 & 0.335 & 0.383 & 0.283 & 0.353 & 0.361 & 0.414 & 0.306 & 0.385 \\
\hline All & & & & & & 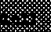 & & \% & X. \\
\hline & & & & & & & & & \\
\hline
\end{tabular}

Since a unified metric performed the best under all conditions, only results pertaining to the unified metric are reported from this point on. The regression results for the unified metric are presented in Table 6. The results depict the significant variables and their corresponding weights (beta values) and level of significance.

Table 6. Regression Equation Output

\begin{tabular}{|c|c|c|c|c|c|}
\hline & $\begin{array}{l}\text { Unstandardized } \\
\text { Coefficients }\end{array}$ & & $\begin{array}{c}\text { Standardized } \\
\text { Coefficients }\end{array}$ & $\mathbf{t}$ & Sig. \\
\hline & $\mathbf{B}$ & Std. Error & Beta & & \\
\hline (Constant) & 1.699 & .207 & & 8.188 & .000 \\
\hline $1=$ low sector, $2=$ high sector & .695 & .084 & .254 & 8.306 & .000 \\
\hline ac_count_sqrd & $-4.406 \mathrm{E}-03$ & .001 & -.263 & -6.371 & .000 \\
\hline TECH CENTER_AD2 & 683.138 & 75.150 & .242 & 9.090 & .000 \\
\hline sector volume/aircraft & $-2.269 E-04$ & .000 & -.648 & -16.182 & .000 \\
\hline TECH CENTER_DOFI & -1.057E-02 & .003 & -.056 & -3.038 & .002 \\
\hline sector volume & 1.865E-05 & .000 & .643 & 14.170 & .000 \\
\hline NASA-1_C1 & 1.161 & .229 & .215 & 5.073 & .000 \\
\hline NASA-1_C4 & .302 & .132 & .044 & 2.279 & .023 \\
\hline NASA-1_C6 & .123 & .055 & .028 & 2.247 & .025 \\
\hline NASA-1_C8 & 4.819E-02 & .017 & .040 & 2.799 & .005 \\
\hline NASA-1_C9 & 6.075E-03 & .002 & .039 & 2.537 & .011 \\
\hline NASA-1_C14 & 5.104E-03 & .002 & .118 & 2.713 & .007 \\
\hline NASA-1_C15 & -1.907 & .634 & -.161 & -3.008 & .003 \\
\hline NASA-2_NH & .128 & .035 & .047 & 3.672 & .000 \\
\hline NASA-2_NA & $-5.408 E-02$ & .020 & -.072 & -2.739 & .006 \\
\hline NASA-2_S25 & 8.303E-02 & .028 & .045 & 2.962 & .003 \\
\hline MET_ac_count & .101 & .023 & .161 & 4.392 & .000 \\
\hline MET_density & $-6.411 \mathrm{E}-03$ & .001 & -.168 & -7.943 & .000 \\
\hline MET_conflict neighbors & $\begin{array}{r}-.118 \\
\end{array}$ & .020 & -.260 & -6.007 & .000 \\
\hline MET_conflict near boundary & 8.733E-02 & .015 & .430 & 5.792 & .000 \\
\hline MET_heading variation & $-1.867 E-02$ & .006 & -.039 & -2.888 & .004 \\
\hline MET_boundary proximity & -.321 & .078 & -.112 & -4.118 & .000 \\
\hline MET_airspace structure & 3.257E-02 & .003 & .215 & 10.506 & .000 \\
\hline
\end{tabular}

\section{Model Testing}

Results for Instantaneous DD Predictions

A performance assessment of the unified DD metric was conducted using the second group of data. The graph of the DD values, complexity ratings, and a model based on only aircraft count indicates that the DD model follows the complexity ratings better than the model based on aircraft count only. Additionally, the $\mathrm{R}$ value for the first group of data is higher for the DD based model than the aircraft count based model.

Note: CSRATING refers to controller and supervisor complexity ratings. 


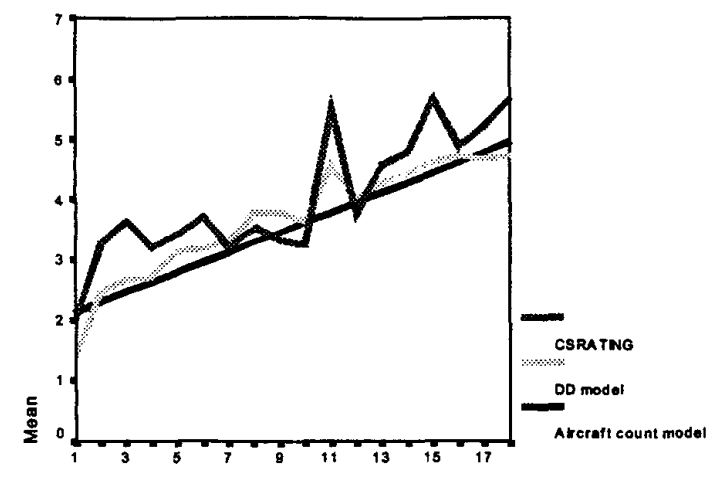

Alrcraft Count

Figure 2. Performance of DD Model

Note: Model 1: CS rating $=1.970+$ $0.165^{*} \mathrm{Ac}$ count, $\mathrm{R}=0.479$, Model 2 : $\mathrm{CS}$ rating $=$ DD equation, $R=0.624$.

Table 7 depicts that the difference between the DD output and the actual complexity ratings. $62.7 \%$ of the observations from the second data group are within 1 unit difference from the actual complexity ratings and $23.1 \%$ of the observations match the ratings exactly. Less than $10 \%$ of the differences are greater than 2 units.

Table 7. Difference Between DD and Complexity Ratings

\begin{tabular}{|ll|r|r|r|r|}
\hline & & Frequency & Percent & Velld Percont & \multicolumn{1}{c|}{$\begin{array}{c}\text { Cumulative } \\
\text { Percont }\end{array}$} \\
\hline Valld & -4.00 & 7 & .6 & .8 & .8 \\
& -3.00 & 17 & 1.8 & 1.8 & 2.7 \\
-2.00 & 109 & 10.1 & 12.5 & 15.2 \\
-1.00 & 243 & 22.5 & 27.8 & 43.0 \\
.00 & 250 & 23.1 & 28.6 & 71.5 \\
1.00 & 185 & 17.1 & 21.1 & 92.7 \\
2.00 & 62 & 5.7 & 7.1 & 99.8 \\
& 3.00 & 2 & .2 & .2 & 100.0 \\
& Total & 875 & 81.0 & 100.0 & \\
Missing & System & 205 & 19.0 & & \\
Total & & 1080 & 100.0 & & \\
\hline
\end{tabular}

Table 8 shows the comparison between the performance of the DD based model and the aircraft count based model for predicting complexity ratings for the second data group. The results indicate that the mean absolute difference, Root Mean Square (RMS) difference, and standard deviation of difference between the actual complexity ratings and model based predictions were smaller for the DD based model. This implies that the DD based model is better at predicting complexity than the model based only on the aircraft count.
Table 8. Performance Measures for DD Based and Aircraft Count Based Model

\begin{tabular}{|c|c|c|c|c|}
\hline \multicolumn{5}{|c|}{ Descriptive Statistics } \\
\hline & Minimum & Maximum & Mean & Std. Deviation \\
\hline CSRATING & 1.0 & 7.0 & 3.685 & 1.4084 \\
\hline 05 based modes & 1.00 & 5.00 & 3.2545 & .90603 \\
\hline $\begin{array}{l}\text { Absoture } \\
\text { Difference }\end{array}$ & .00 & 4.05 & & \\
\hline RMS & N/A & N/A & 1.2200 & N/A \\
\hline $\begin{array}{l}\text { Aircraft count } \\
\text { based mode! }\end{array}$ & 2.13 & 4.94 & 3.0865 & .62208 \\
\hline $\begin{array}{l}\text { Absolute } \\
\text { Difference }\end{array}$ & .0 & 4.7 & 1.233 & .8779 \\
\hline RMS & N/A & N/A & 1.5100 & N/A \\
\hline
\end{tabular}

Figure 3 shows that the mean absolute difference (between complexity predicted by DD based model and complexity ratings for the second data group) was the lowest when the complexity ratings were closer to 3 . The mean absolute difference increased as the complexity ratings were either at the higher or lower end $(1,6$, or 7$)$. This could be because the first data group contained a higher percentage of $2,3,4$, and 5 complexity ratings and a fewer percentage of 6 and 7 ratings.

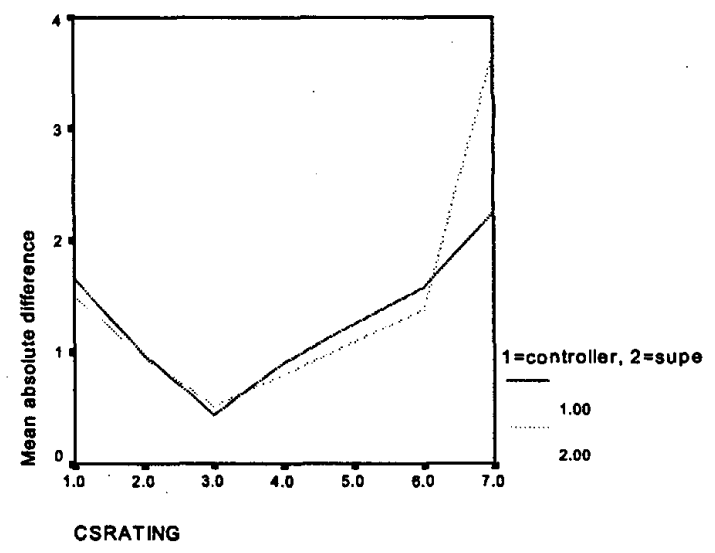

Figure 3. Mean Absolute Difference for Different Complexity Ratings

\section{Results of DD Prediction Model}

The DD researchers were interested in determining if DD representing complexity could be predicted ahead of time. Therefore, they developed another DD equation on the first group of data. The purpose of this equation was to predict DD up to 120 minutes ahead of an actual instance. If the DD predictions were relatively accurate with larger look-ahead times, they could provide valuable insight and assist in planning traffic flow 
changes, sector level staffing needs, dynamic resectorization, and other operational decisions.

The DD equation with look-ahead time as an added variable, the original DD equation, the aircraft count based model, and the complexity ratings were compared for accuracy. Figure 4 shows that the model based on DD with look-ahead time included closely follows the complexity ratings (i.e., CSRating). The original DD model used for instantaneous DD performs the worst and further validates that the look-ahead time must be part of the predictions. This indicates that the DD predictions are dependent on the look-ahead time. This makes sense, as more information is available about flights and weather as the prediction horizon narrows down.

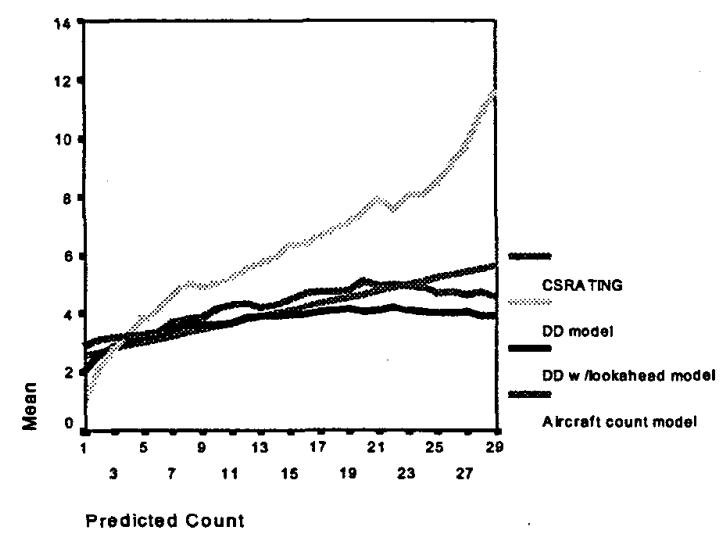

Figure 4. Predicted DD

Note: $\mathrm{CS}$ rating $=2.481+0.110^{*}$ Pred count, $\mathrm{R}=$ $0.411, \mathrm{CS}$ rating $=\mathrm{DD}$ equation + look $-\mathrm{ahead}, \mathrm{R}=$ 0.633

Figure 5 displays how stable the predicted DD values were across look-ahead time for the second data group. The DD with look-ahead time based model provides fairly stable predictions.

Interestingly, the model based on aircraft count also performs fairly well. However, the raw predicted aircraft count varies considerably with look-ahead time.

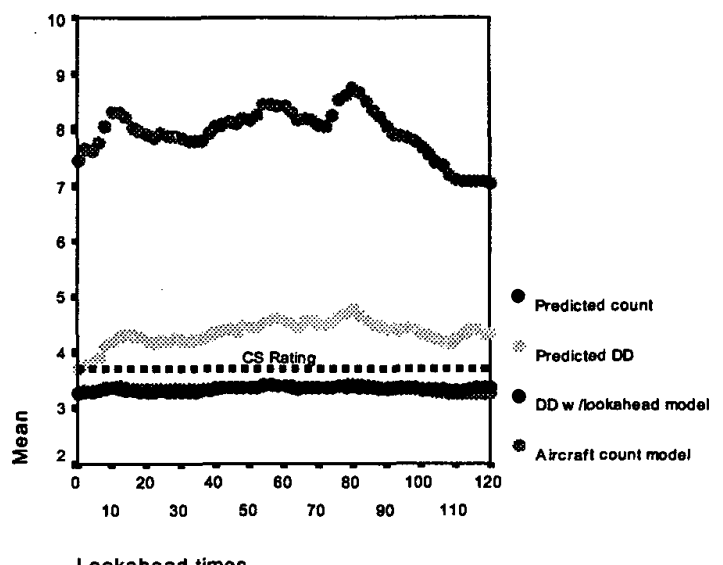

Figure 5. Stability of Predicted DD

Tables 9 and 10 show the performance comparisons of DD with look-ahead time based model, the instantaneous DD based model, and the model based on aircraft count only. The mean absolute difference, standard deviation of absolute difference, and the RMS error are all smaller for DD based model with look-ahead time. Hence, the DD based model with look-ahead time seems to better predict the DD up to 120 minutes ahead of an instance.

Table 9. Performance of Predicted DD

\begin{tabular}{|c|c|c|c|c|}
\hline \multicolumn{5}{|c|}{ Deseriptive stattetics } \\
\hline & Minimum & Maximum & Mean & Std. Deviation \\
\hline PREDCOOUN & 0 & 29 & 7.42 & 5.167 \\
\hline CSRATING & 1.00 & 6.17 & 3.7934 & 1.22984 \\
\hline DD with lookahead & 1.25 & 5.16 & 3.3545 & .72670 \\
\hline Instantaneous DD & .16 & 16.94 & 4.3581 & 2.03400 \\
\hline $\begin{array}{l}\text { DD based on predleted } \\
A C \text { count only }\end{array}$ & 2.48 & 5.67 & 3.2973 & .56841 \\
\hline $\begin{array}{l}\text { Absolute difference for } \\
\text { DD with lookahead }\end{array}$ & .00 & 2.94 & & \\
\hline $\begin{array}{l}\text { Abeolute difference for } \\
\text { Instantaneous DD model }\end{array}$ & .00 & 14.61 & 1.4410 & 1.38430 \\
\hline $\begin{array}{l}\text { Absolute difference for } \\
\text { model based on } \\
\text { predicted AC count }\end{array}$ & .01 & 2.92 & 1.0474 & .69193 \\
\hline $\begin{array}{l}\text { RMS for DD whth } \\
\text { tookahead model }\end{array}$ & N/2 & N/a & & N/a \\
\hline $\begin{array}{l}\text { RMS for Ingtantaneous } \\
\text { OD model }\end{array}$ & N/a & N/a & 1.9900 & $N / a$ \\
\hline $\begin{array}{l}\text { RMS for model based on } \\
\text { predicted AC count }\end{array}$ & N/a & N/a & 1.2500 & $N / a$ \\
\hline
\end{tabular}


Table 10. Performance Of Predicted DD Across Different Look-Ahead Times

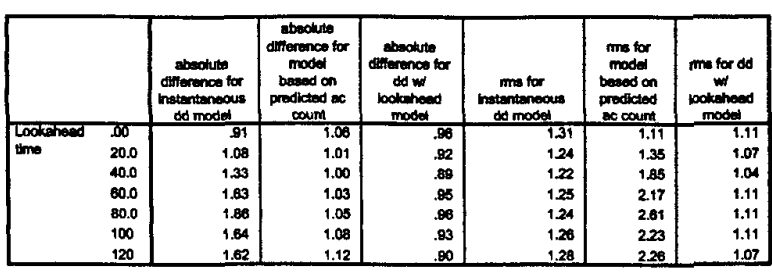

The DD with look-ahead time model (i.e., prediction intervals built into equation) performs better than a model based on instantaneous DD only. DD appears to be more stable over time than predicted number of aircraft and DD appears to be more accurate over time than predicted number of aircraft.

\section{Overall Conclusions}

- The DD metrics have promise, most notably as a unified metric with contributing variables from the FAA WJHTC/Titan Systems, NASA, and Wyndemere/Metron metrics.

- The DD metrics perform better than aircraft count which is the basis of the presently used complexity gauge.

- The models can be further developed and tested with techniques such as neural networks, genetic algorithms, and non-linear regression.

- The current study used ETMS as the raw source of traffic data. However, using more frequently updated data, such as System Analysis and Recording, Center TRACON Automation System, or a combination of the above could further increase the accuracy of aircraft positions.

- The researchers recommend using the DD metric in the simulation environment and plan to continue fine tuning the variables and their weights. Subsequently, an operational prototype could be deployed at a test site for hands-on evaluations.

\section{References}

[1] RTCA Task Force 3 Free Flight Implementation Report, 1995, RTCA: Washington DC.

[2] Laudeman, I.V., Brasil, C. L., \& Branstrom, R., 1996, Air Traffic Control in Restructured Airspace: A Study in Tactical Decision-Making, Power point presentation.

[3] Federal Aviation Administration, 2001, The Measure of Air Traffic Control Sector Complexity for the En Route Environment: Phase II Experiment Plan, FAA WJHTC Internal Document.

[4] Mogford, R.H, Guttman, J.A., Morrow, S. L., \& Kopardekar, P., 1995, The complexity construct in Air Traffic Control: A review and Synthesis of the Literature, DOT/FAA/CT-TN-95/22, FAA Technical Center: Atlantic City.

[5] Kopardekar, P., 2000, Dynamic Density: $A$ Review of Proposed Variables, FAA WJHTC Internal Document.

[6] Federal Aviation Administration, 2002, Dynamic Density Metric Development and Validation Research Management Plan, Living document.

[7] Chatterji, G.B. \& Sridhar B., 2001, Measures for Air Traffic Controller Workload Prediction, Proceedings of the First AIAA Aircraft Technology, Integration, and Operations Forum, Los Angeles, CA.

[8] Laudeman, I.V., Shelden, S.G., Branstrom, R., \& Brasil, C.L., 1999, Dynamic Density: An Air Traffic Management Metric, NASA-TM-1998112226.

[9] Sridhar, B., Sheth, K.S., \& Grabbe, S., Airspace Complexity and its Application in Air Traffic Management, $2^{\text {nd }}$ USA/Europe Air Traffic Management R\&D Seminar, Orlando, Florida.

[10] Wyndemere, 1996, An Evaluation of Air Traffic Control Complexity, Final Report, Contract Number NAS2-14284 (NASA contract). 